\title{
Inheritance of hypertrophic cardiomyopathy: a cross sectional and $M$ mode echocardiographic study of 50 families
}

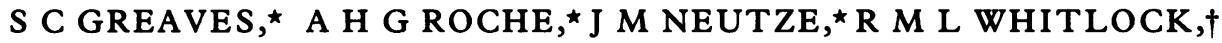 \\ A $M$ O VEALE $\ddagger$ \\ From the Departments of Cardiology $y^{\star}$ and Physiology, $\dagger$ Green Lane Hospital, and University of Auckland \\ School of Medicine, $\ddagger$ Auckland, New Zealand
}

SUMMARY To determine the mode of inheritance of hypertrophic cardiomyopathy 193 first degree relatives (parents, siblings, and offspring) of 50 patients with hypertrophic cardiomyopathy were assessed by clinical examination, electrocardiography, $\mathbf{M}$ mode and cross sectional echocardiography, and necropsy when available. Thirty nine (20\%) first degree relatives had hypertrophic cardiomyopathy-37\% of parents, $25 \%$ of siblings, and $8 \%$ of offspring. Eight $(23 \%)$ of 35 affected relatives diagnosed by echocardiography had normal clinical and electrocardiographic findings. In the total study group $43 \%$ of the male population and $30 \%$ of the female population were affected. This difference is statistically significant. In 28/50 families there was familial occurrence of hypertrophic cardiomyopathy. Familial occurrence was demonstrated in 17 of 18 families in which five or more family members were assessed. In 15 families the pattern of inheritance was consistent with an autosomal dominant trait; in the other 13 the affected members were identified in a single generation and the pattern of inheritance could not be determined.

The familial occurrence of hypertrophic cardiomyopathy is well documented. Before the development of echocardiography one third of cases were considered "genetic" and two thirds "sporadic". 12 With the widespread use of echocardiography in the 1970s, many cases of hypertrophic cardiomyopathy were diagnosed in patients without clinical evidence of the disease. ${ }^{3} \mathrm{M}$ Mode echocardiography studies suggested that about $50 \%$ of first degree relatives of cases were affected and that hypertrophic cardiomyopathy was probably always transmitted as an autosomal dominant trait with a high degree of penetrance. ${ }^{4-6}$

The accuracy of echocardiographic diagnosis of hypertrophic cardiomyopathy has increased with the introduction of cross sectional echocardiography, better understanding of the criteria

Requests for reprints to Dr A H G Roche, Department of Cardiology, Green Lane Hospital, Auckland, New Zealand.

Accepted for publication 9 April 1987 for the diagnosis, ${ }^{7}$ and an appreciation of the morphological spectrum of the disease. ${ }^{89}$ In a recent cross sectional and $M$ mode echocardiographic study of 70 families with hypertrophic cardiomyopathy $56 \%$ showed familial occurrence of the disease. ${ }^{10}$ Twenty two per cent of first degree relatives were affected. Parents and siblings were affected more frequently than offspring. The most common pattern of inheritance was autosomal dominant but $44 \%$ of cases were apparently sporadic.

We have investigated the inheritance of this disease in a New Zealand population.

\section{Patients and methods}

\section{SELECTION OF PATIENTS}

The study protocol was approved by the Green Lane Hospital ethics committee. Seventy patients met our selection criteria as probands: $(a)$ review at Green Lane Hospital between January 1964 and May 1984, (b) characteristic clinical features of hypertrophic cardiomyopathy supported by echocardiographic or haemodynamic and angio- 
cardiographic studies or both, (c) residence within $200 \mathrm{~km}$ of Green Lane Hospital at time of presentation, $(d)$ presentation independent of a family history of hypertrophic cardiomyopathy. Dead patients were included as probands. In two instances in which two first degree relatives met these criteria the subject presenting first was considered to be the proband. Four probands were related (an uncle and nephew in one family, two first cousins in a second family). Twenty patients were excluded: 12 were lost to follow up, six had no first degree relatives available for study, and two were unwilling to participate in the study.

During 1984, 39 probands were reassessed at Green Lane Hospital. Nine probands had died, and two were not available for reassessment. The 50 probands had a total of 341 first degree relatives. One hundred and seventy eight first degree relatives assessed at Green Lane Hospital had cross sectional and $M$ mode echocardiographic studies adequate to confirm or exclude hypertrophic cardiomyopathy. Two first degree relatives had been previously assessed at Green Lane Hospital. Diagnostic information was obtained on eight first degree relatives assessed in other centres, ${ }^{\star}$ and necropsy information adequate to confirm (four relatives) or exclude (one relative) hypertrophic cardiomyopathy was obtained on five first degree relatives.

We attempted to establish the cause of death in all dead first degree relatives from death certification, medical, hospital, and necropsy reports. We were unable to confirm or exclude hypertrophic cardiomyopathy in 148 first degree relatives ( 82 were dead and inadequate clinical/necropsy data were available, 47 lived in areas too remote from Green Lane Hospital, 10 were unwilling to participate in the study, and in nine echocardiographic studies were technically inadequate or systemic hypertension precluded definitive classification).

The final study group consisted of 50 probands

*Information supplied by Dr A P Poole, Southland Hospital, Invercargill; and Dr R N Easthope, Wellington Hospital.
(28 male, 22 female) and 193 first degree relatives (100 male, 93 female) (table 1). Twenty two probands and two first degree relatives had undergone septal myotomy-myectomy at Green Lane Hospital. All subjects assessed at Green Lane Hospital underwent clinical examination, 13 lead electrocardiography, and $M$ mode and cross sectional echocardiography.

A detailed family history of proband patients was taken including all first degree and second degree (grandchildren, nieces and nephews, aunts and uncles, grandparents) relatives. There was no evidence of consanguinity in any family.

\section{SYMPTOMS AND CLINICAL EXAMINATION}

The symptomatic state was recorded preoperatively for probands (22) and relatives (2) undergoing septal myotomy-myectomy and at time of assessment for subjects (65) not treated surgically. The symptomatic state was not recorded in one affected first degree relative because of severe coexisting obstructive lung disease and in two relatives the symptomatic state was unknown. Resting supine blood pressure was measured on two occasions at least 60 minutes apart and the lower of the two measurements was recorded. Subjects were classified as hypertensive if $(a)$ there was a history of hypertension or $(b)$ blood pressures were consistently $>140 / 90 \mathrm{~mm} \mathrm{Hg}$. Audible fourth heart sounds (or a palpable presystolic impulse), systolic murmurs of grade II/VI intensity or greater, and diastolic murmurs were recorded as abnormal. Third heart sounds in patients less than 20 years and systolic murmurs of grade I/VI intensity were not recorded as abnormal.

\section{ELECTROCARDIOGRAPHY}

Electrocardiogram data were available for review in all probands and in 184 of 193 first degree relatives. Left ventricular hypertrophy, atrial hypertrophy, abnormal $Q$ waves $(>0.04 \mathrm{~s}$ and $>25 \%$ of the $R$ wave), rhythm and conduction abnormalities were documented on a resting 13 lead electrocardiogram

Table 1 Demographic data in probands, affected relatives, and unaffected relatives, excluding relatives with "probable" hypertrophic cardiomyopathy

\begin{tabular}{|c|c|c|c|c|c|c|c|}
\hline \multirow{2}{*}{$\begin{array}{l}\text { Subject } \\
\text { Characteristics }\end{array}$} & \multirow[b]{2}{*}{ Probands } & \multicolumn{2}{|l|}{ Parents } & \multicolumn{2}{|l|}{ Siblings } & \multicolumn{2}{|l|}{ Offspring } \\
\hline & & Affected & Unaffected & Affected & Unaffected & Affected & Unaffected \\
\hline \multicolumn{8}{|l|}{$\begin{array}{l}\text { No with definite } \\
\text { hypertrophic }\end{array}$} \\
\hline $\begin{array}{l}\text { cardiomyopathy } \\
\text { Mean age (years) } \\
\text { (SD) } \\
\text { Median age (years) } \\
\text { Age range (years) }\end{array}$ & $\begin{array}{l}50 \\
54 \cdot 7 \\
(10 \cdot 1) \\
60 \\
43-61\end{array}$ & $\begin{array}{l}11 \\
62 \cdot 0 \\
(16 \cdot 1) \\
67 \\
32-81\end{array}$ & $\begin{array}{l}16 \\
61 \cdot 1 \\
(14 \cdot 9) \\
65 \\
34-81\end{array}$ & $\begin{array}{l}22 \\
39 \cdot 4 \\
(17 \cdot 9) \\
36 \\
7-75\end{array}$ & $\begin{array}{l}64 \\
37 \cdot 3 \\
(16 \cdot 5) \\
39 \\
8-72\end{array}$ & $\begin{array}{l}6 \\
26 \cdot 5 \\
(21 \cdot 0) \\
24 \cdot 5 \\
8 / 12^{\star}-63\end{array}$ & $\begin{array}{l}66 \\
23 \cdot 2 \\
(12 \cdot 8) \\
22 \cdot 5 \\
3-60\end{array}$ \\
\hline
\end{tabular}

^Eight months. 
The minimum criterion for left ventricular hypertrophy was a voltage $\left(\mathrm{SV}_{1}+\mathrm{RV}_{6}{ }^{2}\right.$ or $\left.\mathrm{SV}_{2}+\mathrm{RV}_{6}\right)$ of $35-60 \mathrm{~mm}(45-60 \mathrm{~mm}$ in children less than 18 years). ${ }^{11}$ Electrocardiogram data were recorded preoperatively in subjects undergoing septal myotomymyectomy.

\section{ECHOCARDIOGRAPHY}

Cross sectional echocardiographic studies were performed with a Toshiba SSH 10A electronic phased array sector scanner with a $2.4 \mathrm{MHz}$ transducer. Images were recorded on $3 / 4$ inch video cassette for subsequent review. $M$ mode echoes were obtained simultaneously with direct visualisation by means of the cross sectional scanner and were recorded with a Honeywell model L56AHS stripchart recorder interfaced with the sector scanner.

The thickness of the interventricular septum and posterior free wall was measured at the onset of the QRS complex in the same cardiac cycle with the ultrasound beam directed slightly caudal to the mitral valve leaflets. The leading edge method was used. ${ }^{12} \mathrm{M}$ mode measurements were compared with normal values related to age and body weight measured during the same phase of the cardiac cycle. ${ }^{13}$

Cross sectional echocardiograms of parasternal long and short axis, apical four and two chamber, and subcostal views were recorded. ${ }^{12}$ Short axis left ventricular views were obtained by orienting the transducer perpendicularly to the long axis of the left ventricle from a parasternal location where the septum was most nearly perpendicular to the ultrasound beam. Serial short axis views were obtained during a sweep performed by maintaining the transducer in a fixed location on the chest wall and angling the image plane from aorta to apex. Emphasis was placed on achieving images in which the entire left ventricular endocardium and epicardium were well defined and in which the left ventricular cavity was most nearly circular.

Assessment of hypertrophy on cross sectional recordings was assessed by careful review of the real time recording and by measurement of wall thickness directly from the video screen with callipers. All $\mathrm{M}$ mode and cross sectional echocardiographic recordings were assessed by two independent observers (SCG, AHGR). Where there was disagreement (three patients) the echocardiograms were jointly reviewed and a decision reached.

\section{DIAGNOSTIC CRITERIA FOR HYPERTROPHIC CARDIOMYOPATHY}

The diagnostic criterion for hypertrophic cardiomyopathy was left ventricular hypertrophy without dilatation of the left ventricular cavity in the absence of another cardiac or systemic disease capable of causing left ventricular hypertrophy. On $M$ mode echocardiography, the criteria for left ventricular hypertrophy was increased wall thickness (interventricular septum (IVS) only or interventricular septum and posterior free wall (PFW)) clearly greater than the upper $95 \%$ confidence interval. ${ }^{13}$ Asymmetrical septal hypertrophy (IVS:PFW $\geqslant 1.3$ ) without clear evidence of left ventricular hypertrophy was not a criterion (16 subjects). On cross sectional echocardiography hypertrophy was considered to be present if wall thickness was clearly $\geqslant 15 \mathrm{~mm}$ in subjects who were $\geqslant 16$ years. In subjects $<16$ years hypertrophy was considered to be present if wall thickness was $\leqslant 3 \mathrm{~mm}$ than the upper $95 \%$ confidence interval of $M$ mode recordings. ${ }^{13}$

Five probands and six first degree relatives designated as having hypertrophic cardiomyopathy had a history of systemic hypertension but were included because of clinical features suggestive of hypertrophic cardiomyopathy or because the degree of left ventricular hypertrophy on echocardiography clearly exceeded that attributable to the hypertension.

Eight relatives were designated as having probable but not definite hypertrophic cardiomyopathy because (a) systemic hypertension obscured the diagnosis (three subjects); (b) ventricular wall thicknesses were borderline (four subjects); $(c)$ in one dead subject available clinical data strongly suggested hypertrophic cardiomyopathy but no diagnostic echocardiographic or necropsy information was available.

\section{STATISTICAL ANALYSIS}

Modes of inheritance in the study group were analysed by a simple segregation analysis which determined the proportion of first degree relatives affected by hypertrophic cardiomyopathy. Affected first degree relatives were counted after excluding the proband from the pedigree.

The $95 \%$ confidence intervals for segregation ratios (proportion of first degree relatives affected) are the $95 \%$ confidence intervals for the binomial distribution. They were achieved by logistic transformation, which gives asymmetric confidence limits. This gives a more precise definition of group limits than methods giving symmetrical limits. ${ }^{14}$

Student's unpaired $t$ test and $\chi^{2}$ test were used where appropriate.

\section{Results}

\section{DIAGNOSIS IN RELATIVES}

Definite hypertrophic cardiomyopathy was diagnosed in 35 first degree relatives by echocardiography and in four by review of necropsy and 
clinical records. Of the 35 diagnosed by echocardiography, eight $(23 \%)$ had normal clinical examinations and electrocardiogram, one $(3 \%)$ had an abnormal clinical examination but normal electrocardiograms, $10(29 \%)$ had an abnormal electrocardiogram but normal clinical examination, and 16 $(46 \%)$ had abnormal features on both clinical examination and electrocardiograms (fig 1). Of these 35 relatives diagnosed by echocardiography, $11(31 \%)$ had previously been diagnosed as having hypertrophic cardiomyopathy, six (17\%) had been previously known to have a cardiac abnormality not diagnosed as hypertrophic cardiomyopathy, and 18 $(51 \%)$ were not known to have any cardiac abnormality before the study.

\section{SEGREGATION RATIO}

Thirty nine (20\%) of 193 first degree relatives were affected with hypertrophic cardiomyopathy (fig 2). If those patients classified as having probable hypertrophic cardiomyopathy are included, 47/193 (24\%) were affected. The frequency of definite cases in offspring $(6 / 74,8 \%)$ was significantly less than that in siblings $(22 / 89,25 \%, \mathrm{p}<0.005)$ or parents $(11 / 30,37 \%, \mathrm{p}<0.005)$ (fig 2). The difference between parents and siblings was not statistically significant. If those patients with probable hypertrophic cardiomyopathy are included, $47 \%$ of par-

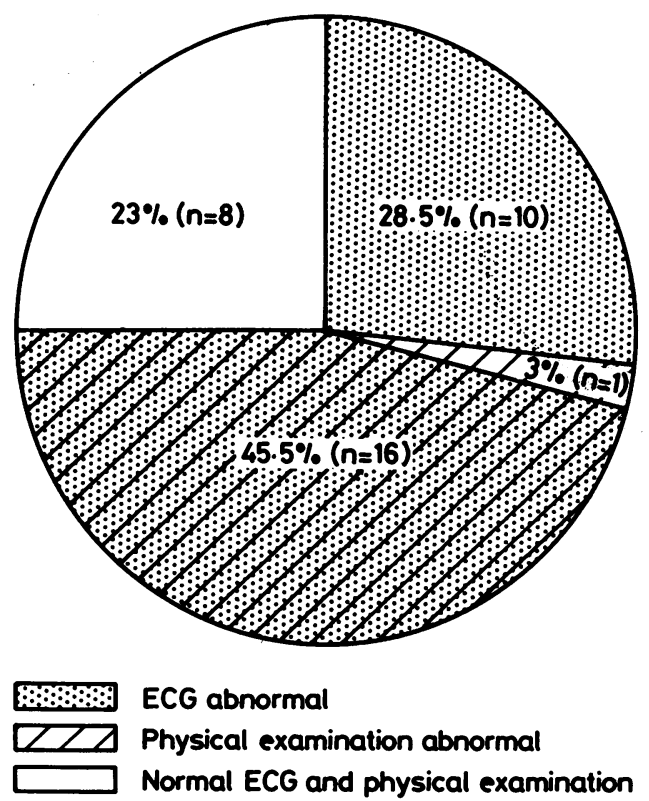

Fig 1 Numbers and percentages of 35 first degree relatives diagnosed by echocardiography as having hypertrophic cardiomyopathy who also had clinical and electrocardiographic abnormalities.

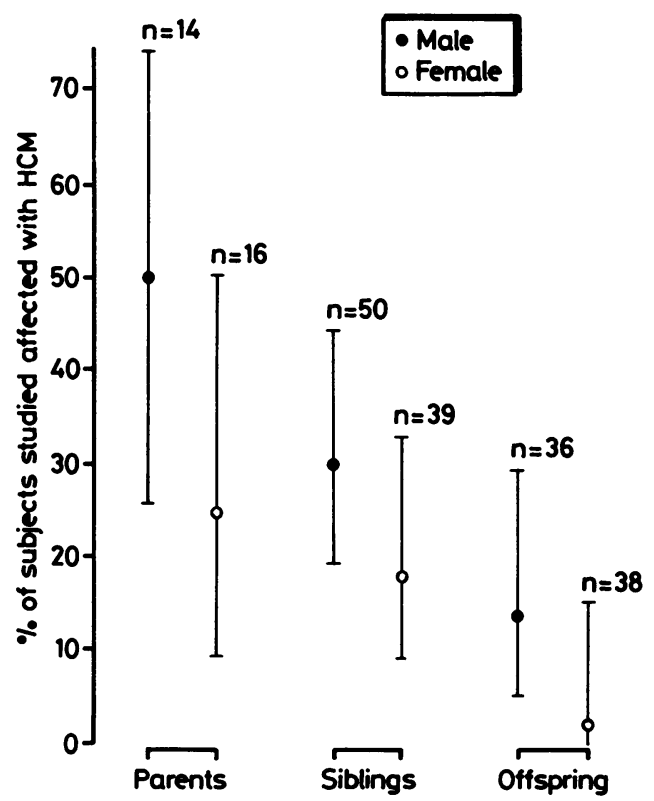

Fig 2 Numbers and percentages of parents, siblings, and offspring studied with definite hypertrophic cardiomyopathy. Ninety five per cent confidence intervals are shown and each group is separated into male and female subjects.

ents, $28 \%$ of siblings, and $11 \%$ of offspring were affected (difference between parents and siblings, NS; parents and offspring, $p<0.001$; siblings and offspring, $p<0.005)$. Among parents, siblings, and offspring males were affected more frequently than females (fig 2). In the total group of probands and first degree relatives, $55(43 \%)$ of 128 of the male population and $34(30 \%)$ of 115 of the female population were affected $(p<0.05)$.

Twenty eight of 50 pedigrees showed familial occurrence of definite hypertrophic cardiomyopathy. The frequency with which hypertrophic cardiomyopathy was identified in relatives increased with the number of subjects studied (table 2). In these 28 pedigrees, $67 \%$ of all first degree relatives were studied. In the 22 pedigrees in which no relatives were affected, $40 \%$ of all first degree relatives were studied $(p<0.01)$.

All pedigrees were examined for features of autosomal dominant, recessive, and $\mathrm{X}$-linked inheritance. In 15 pedigrees with hypertrophic cardiomyopathy in successive generations there were 16 instances of transmission from one generation to the next. Male to male transmission occurred in eight cases, male to female transmission in three cases, female to female transmission in one case, and female to male transmission in four cases. Male to male transmission excludes $\mathrm{X}$-linked recessive 
Table 2 Frequency of familial hypertrophic cardiomyopathy (HCM) related to the number of first degree relatives studied

\begin{tabular}{lcl}
\hline $\begin{array}{l}\text { Number of } \\
\text { first degree } \\
\text { relatives studied }\end{array}$ & $\begin{array}{l}\text { Number of } \\
\text { pedigrees }\end{array}$ & $\begin{array}{l}\text { Number and percentage } \\
\text { of pedigrees with familial } \\
\text { HCM }\end{array}$ \\
\hline 1 & 11 & $3(27 \%)$ \\
2 & 8 & $5(63 \%)$ \\
3 & 4 & $1(25 \%)$ \\
4 & 9 & $2(22 \%)$ \\
5 & 5 & $4(80 \%)$ \\
6 & 5 & $5(100 \%)$ \\
7 & 4 & $3(100 \%)$ \\
8 & 3 & $3(100 \%)$ \\
9 & & \\
10 & 1 & $1(100 \%)$ \\
11 & 193 & 28 \\
Total & & \\
\hline
\end{tabular}

inheritance and $\mathrm{X}$-linked dominant inheritance.

In $15 / 28$ pedigrees the pattern of inheritance was most consistent with an autosomal dominant traitthat is affected relatives were identified in successive generations. In the other 13 pedigrees affected relatives were identified in only one generation and the pattern of inheritance could not be specified. Detection of hypertrophic cardiomyopathy in parents and siblings (but not offspring) of probands was related to the percentage studied (table 3 ).

For seven probands both parents were available for study. One parent was affected in five pairs and both parents were normal in two pairs. All siblings in the latter two families were studied. In the first, one of five siblings was affected and in the second all three siblings were normal. Neither of the two probands had children. These two pedigrees may represent recessive inheritance, incomplete penetrance or, in the second case, sporadic disease.

The low frequency of hypertrophic cardiomyopathy in offspring raises the possibility that hypertrophic cardiomyopathy is a progressive disorder which may develop later in life. Regression equations were derived to determine the change in interventricular septal thickness with age in normal subjects, probands, and affected relatives. $y=b x+a( \pm s y: x)$ where $y=$ septal thickness (as percentage of predicted); $x=$ age; $b=$ slope; $a$ $=$ intercept $; \mathbf{s}=\mathrm{a}$ constant.

When corrected for weight and for the normal slight increase that occurs with age, ${ }^{12}$ interventricular septal thickness did not change appreciably with age in normal subjects (fig 3$)(p=0.31)$ and tended to be greater with increasing age in affected relatives (fig 4) but this was not statistically significant $(p=0 \cdot 26)$. An apparent inverse trend with age in probands (fig 5) (just significant $p=$ 0.048 ) is probably related to exclusion of severely affected subjects from older age groups by death or operation. The mean and median ages were similar in affected and non-affected parents, siblings, and offspring (table 1). Thus although septal thickness may increase with age we have no clear evidence that hypertrophic cardiomyopathy is a progressive disorder; however, individual serial studies have not been undertaken.

\section{Discussion}

There are several methodological problems and sources of bias that make the study of genetic disease difficult and are relevant to this study. (a) Many individuals with hypertrophic cardiomyopathy are symptom free and would not normally come to clinical attention. Thus the selection of proband patients is biased. Families with more than one affected member are more likely to be ascertained, producing bias against the detection of sporadic cases. (b) The definitive diagnosis of hypertrophic cardiomyopathy usually requires echocardiographic or detailed necropsy study. Because this was a retrospective study such information was not available in 148 first degree relatives and in these individuals hypertrophic cardiomyopathy could not be excluded or confirmed. In addition, a small number of first degree relatives studied could not be classified definitively because of coexisting systemic hypertension.

Previous $\mathbf{M}$ mode echocardiographic studies have

Table 3 Numbers and percentages of relatives studied in pedigrees in which hypertrophic cardiomyopathy (HCM) was identified in successive generations or in a single generation, and in pedigrees with no relatives affected

\begin{tabular}{llll}
\hline & $\begin{array}{l}\text { Number and } \\
\text { percentage of } \\
\text { parents studied }\end{array}$ & $\begin{array}{l}\text { Number and } \\
\text { percentage of } \\
\text { siblings studied }\end{array}$ & $\begin{array}{l}\text { Number and } \\
\text { percentage of } \\
\text { offspring studied }\end{array}$ \\
\hline $\begin{array}{l}\text { HCM identified in successive } \\
\text { generations (15 pedigrees) }\end{array}$ & $16(53 \%)$ & $32(71 \%)$ & $\begin{array}{l}\text { Number and percentage } \\
\text { of all first degree } \\
\text { relatives studied }\end{array}$ \\
$\begin{array}{l}\text { HCM identified in a single } \\
\text { generation (13 pedigrees) }\end{array}$ & $7(27 \%)$ & $38(66 \%)$ & $24(89 \%)$ \\
$\begin{array}{l}\text { HCM not identified in first } \\
\text { degree relatives }\end{array}$ & $\begin{array}{ll}\text { (22 pedigrees) } \\
\text { All pedigrees }\end{array}$ & $30(30 \%)$ & $65(62 \%)$ \\
\hline
\end{tabular}




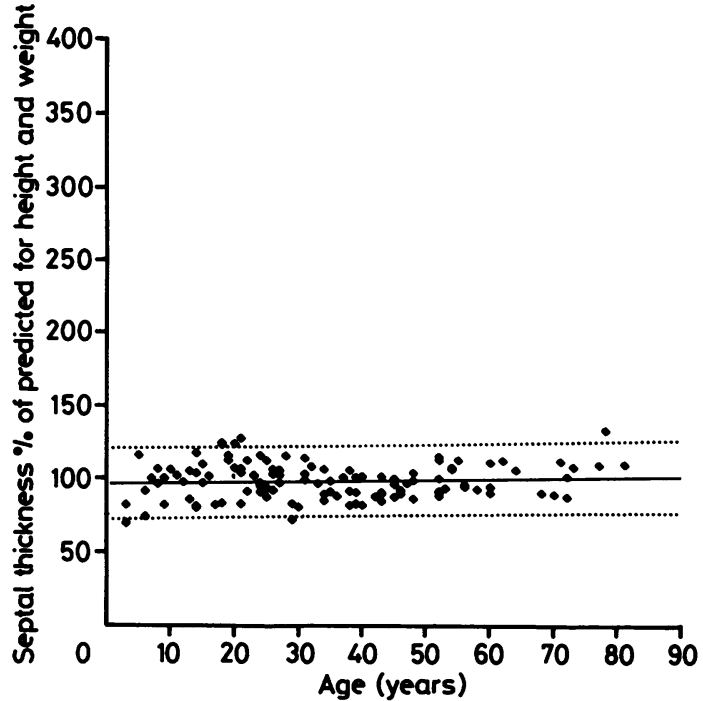

Fig 3 Relation of interventricular septal (IVS) thickness to age in normal subjects (septal thickness expressed as percentage of predicted related to age and body weight). Regression equation: IVS thickness (percentage of predicted $)=0.059590 \times$ age $+97 \cdot 2723( \pm 12 \cdot 1325)$.

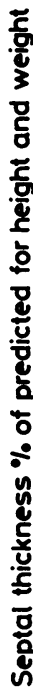
要 400 400
350
300
250
200
150
100
50
0

Fig 4 Relation of interventricular septal (IVS) thickness to age in 22 affected relatives of subjects with hypertrophic cardiomyopathy (septal thickness expressed as percentage of predicted related to age and body weight). Regression equation: IVS thickness (percentage of predicted) = $0.499094 \times$ age $+161.364( \pm 43.0955)$.

suggested that hypertrophic cardiomyopathy is usually transmitted as an autosomal dominant trait with high penetrance. ${ }^{4-6}$ Our data confirm the finding of Maron et $\mathrm{al}^{10}$ that approximately $20 \%$ of first degree relatives of subjects with hypertrophic cardio-

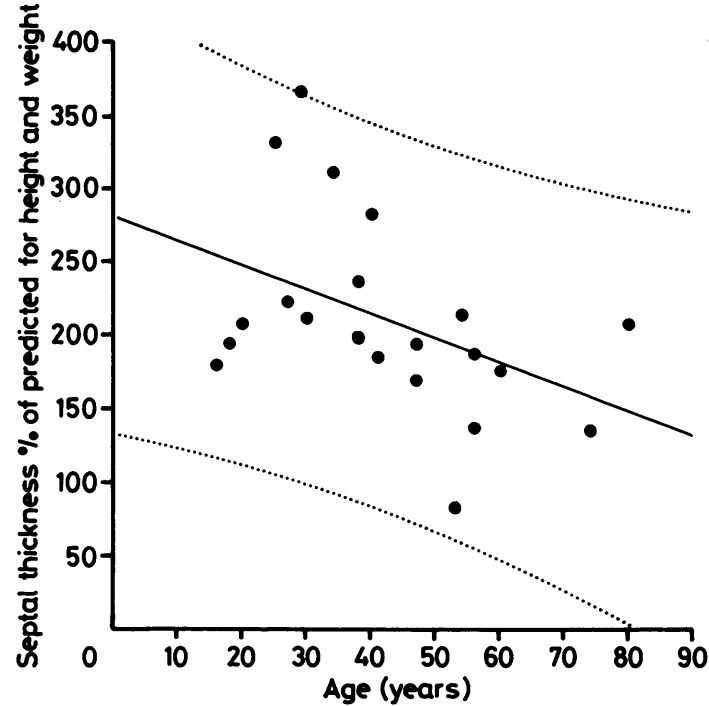

Fig 5 Relation of interventricular septal (IVS) thickness to age in 21 probands with hypertrophic cardiomyopathy (septal thickness expressed as percentage of predicted related to age and body weight). Regression equation: IVS thickness (percentage of predicted $)=-1.65384 \times$ age +281.445 $( \pm 61 \cdot 5441)$.

myopathy are shown to be affected when they are studied by $M$ mode and cross sectional echocardiography.

Factors which may have contributed to the lower yield with cross sectional echocardiography are: $(a)$ differences in population structure (in our study and in that of Maron et al ${ }^{10}$ offspring and siblings were affected significantly less frequently than parents and siblings, and comparatively large numbers of offspring were included in these studies (table 4)); (b) cross sectional echocardiography is more accurate than $M$ mode echocardiography in defining the right and left sides of the interventricular septum and in avoiding oblique angulation of the ultrasound beam; (c) asymmetrical septal hypertrophy (ratio of septal to posterior wall thickness $\geqslant 1 \cdot 3$ ) used by Clark et al and Van Dorp et al, ${ }^{45}$ without clear evidence of left ventricular hypertrophy, is not a reliable diagnostic criterion for hypertrophic cardiomyopathy. Neither is an absolute septal thickness of $\geqslant 1.3 \mathrm{~cm}$ unrelated to age and body weight (Bjarnason $\left.e t a l^{6}\right)$. It is unclear from Clark et al and Van Dorp $e t ~ a l^{45}$ how many individuals were diagnosed solely on the basis of a ratio. Sixteen subjects in our study had asymmetrical septal hypertrophy but were not regarded as having definite hypertrophic cardiomyopathy. Because of inaccurate diagnostic criteria and technical limitations, $M$ mode echocardiography has probably overestimated the percentage of first degree relatives affected in families 
Table 4 Numbers of parents, siblings, and offspring studied in genetic studies of hypertrophic cardiomyopathy

\begin{tabular}{|c|c|c|c|c|c|}
\hline & $\begin{array}{l}\text { Total } \\
\text { relatives studied }\end{array}$ & $\begin{array}{l}\text { No of parents and } \\
\text { siblings studied } \\
\text { as } \% \text { of total }\end{array}$ & $\begin{array}{l}\text { Percentage of } \\
\text { parents and } \\
\text { siblings affected }\end{array}$ & $\begin{array}{l}\text { No of offspring } \\
\text { studied as } \% \text { of } \\
\text { total }\end{array}$ & $\begin{array}{l}\text { Percentage of } \\
\text { offspring affected }\end{array}$ \\
\hline $\begin{array}{l}\text { Clark et al } \\
\text { Bjarnason et al } \\
\text { Maron et al } \\
\text { Greaves et al }\end{array}$ & $\begin{array}{r}105 \\
44 \\
296 \\
193\end{array}$ & $\begin{array}{r}72(69 \%) \\
35(80 \%) \\
157(53 \%) \\
119(62 \%)\end{array}$ & $\begin{array}{l}53 \% \\
46 \% \\
28 \% \\
28 \%\end{array}$ & $\begin{array}{r}33(31 \%) \\
9(20 \%) \\
139(47 \%) \\
74(38 \%)\end{array}$ & $\begin{array}{r}30 \% \\
20 \% \\
14 \% \\
8 \%\end{array}$ \\
\hline
\end{tabular}

Van Dorp et al $^{5}$ excluded from analysis because of inclusion of first cousins.

with hypertrophic cardiomyopathy.

Fifty six per cent of all pedigrees showed familial occurrence of hypertrophic cardiomyopathy. The frequency with which hypertrophic cardiomyopathy was identified in first degree relatives increased with the number of subjects studied. Hypertrophic cardiomyopathy was identified in $67 \%$ of 30 families where three or more first degree relatives were studied, and in $95 \%$ of 18 families where five or more relatives were studied, indicating a strongly familial trait.

On inspection of individual pedigrees, autosomal dominant transmission was documented in $\mathbf{1 5}$ of 28. The 13 pedigrees in which hypertrophic cardiomyopathy was detected in only one generation may reflect different modes of inheritance, reduced penetrance (that is genetic disease not overtly expressed as hypertrophic cardiomyopathy) or failure to identify the disease because of the previously mentioned limitations of a retrospective analysis. In these 13 pedigrees fewer parents were studied, and fewer probands had three generations available for study; in two of these 13 pedigrees, and in 16 of the 22 pedigrees in which hypertrophic cardiomyopathy was not identified in first degree relatives, only one generation was studied, so that autosomal dominant inheritance could not be proved. The 22 apparently isolated cases of hypertrophic cardiomyopathy may in some cases reflect recessive inheritance, new genetic mutation, or non-genetic disease. However, because we included 12 probands with only one or two relatives available for study, it is probable that some have familial disease that could not be confirmed in this study.

The frequency with which hypertrophic cardiomyopathy was found in subgroups of first degree relatives is similar to that noted by Maron et al. ${ }^{10}$ Parents were affected most often and offspring least often. In all subgroups more males were affected than females. In the total group of probands and first degree relatives males were affected significantly more frequently than females $(p<0.05)$. Maron $e t$ al also found a significant difference in the percentages of males $(26 \%)$ and females $(17 \%)$ affected in the total study group $(\mathrm{p}<0.001) .{ }^{10}$
One quarter of affected first degree relatives had normal clinical and electrocardiographic findings and were diagnosed only by echocardiography. The course in this group of patients is uncertain. One of them was the parent of a proband with severe diffuse left ventricular hypertrophy, suggesting that the genetic implications of such an isolated echocardiographic finding may be similar to that of more overt hypertrophic cardiomyopathy.

The major question that arises in genetic counselling is the risk of transmission of the disease to offspring. Only $8 \%$ of offspring were affected in this study. It is possible that hypertrophic cardiomyopathy is a progressive disease that is not always apparent at a young age. Maron et al have documented the spontaneous appearance and progression of left ventricular hypertrophy in adolescent relatives of patients with hypertrophic cardiomyopathy. ${ }^{15}$ Bjarnason $e t$ al found a positive correlation of septal thickness with age. ${ }^{6}$ We were unable to show significant progression of septal hypertrophy in affected individuals and the mean and median ages of affected and unaffected parents, siblings, and offspring were similar. The median age of unaffected offspring was 22.5 years. We therefore do not have evidence that hypertrophic cardiomyopathy is a progressive disease. Further serial studies of individual patients will be necessary to confirm Maron's finding.

This work was supported by grants from the National Heart Foundation of New Zealand and the Green Lane Hospital Research and Educational Fund.

\section{References}

1 Braunwald E, Lambrew CT, Rockoff SD, Ross J Jr, Morrow AG. Idiopathic hypertrophic subaortic stenosis: I. A description of the disease based upon an analysis of 64 patients. Circulation 1964;30(suppl IV):IV-3-119.

2 Frank S, Braunwald E. Idiopathic hypertrophic subaortic stenosis. Clinical analysis of 126 patients with emphasis on the natural history. Circulation 1968;37:759-88. 
3 Henry WL, Clark CE, Epstein SE. Asymmetric septal hypertrophy (ASH): echocardiographic identification of the pathognomonic anatomic abnormality of IHSS. Circulation 1973;47:225-33.

4 Clark CE, Henry WL, Epstein SE. Familial prevalence and genetic transmission of idiopathic hypertrophic subaortic stenosis. N Engl J Med 1973;289:704-14.

5 Van Dorp WG, ten Cate FJ, Vletter WB, Dohman H, Roelandt J. Familial prevalence of asymmetric septal hypertrophy. Eur J Cardiol 1976;4:349-51.

6 Bjarnason I, Jonsson S, Hardarson T. Mode of inheritance of hypertrophic cardiomyopathy in Iceland. Echocardiographic study. Br Heart J 1982;47:122-9.

7 Maron BJ, Epstein SE. Hypertrophic cardiomyopathy. Recent observations regarding the specificity of three hallmarks of the disease: asymmetric septal hypertrophy, septal disorganisation and systolic anterior motion of the anterior mitral leaflet. Am J Cardiol 1980;45:141-54.

8 Maron BJ, Gottdiener JS, Bonow RD, Epstein SE. Hypertrophic cardiomyopathy with unusual locations of left ventricular hypertrophy undetectable by M-mode echocardiography: identification by wideangle, two-dimensional echocardiography. Circulation 1981;63:409-18.
9 Yamaguchi H, Ishimura $T$, Nishiyamas $S$, et al. Hypertrophic nonobstructive cardiomyopathy with giant negative $T$ waves (apical hypertrophy). Ventriculographic and echocardiographic features in $\mathbf{3 0}$ patients. Am J Cardiol 1979;44:401-12.

10 Maron BJ, Nichols PF, Pickle LW, Wesley YE, Mulvihill JJ. Patterns of inheritance in hypertrophic cardiomyopathy: assessment by $\mathbf{M - m o d e}$ and twodimensional echocardiography. Am J Cardiol 1984;53:1087-94.

11 Smith HJ, Neutze JM, Roche AHG, Agnew TM, Barratt-Boyes BG. The natural history of rheumatic aortic regurgitation and the indications for surgery. Br Heart J 1976;38:147-54.

12 Feigenbaum H. Echocardiography. 3rd ed. Philadelphia: Lea and Febiger, 1981:119-39.

13 Henry WL, Gardin JM, Ware JH. Echocardiographic measurements in normal subjects from infancy to old age. Circulation 1980;62:1054-61.

14 Sokal RR, Rolft FJ. Biometry. San Francisco: WH Freeman, 1969:2-5.

15 Maron BJ, Spirito P, Wesley Y, Arce J. Development and progression of left ventricular hypertrophy in children with hypertrophic cardiomyopathy. $N$ Engl J Med 1986;315:610-4. 